\title{
A MODIFIED HYPERBOLIC TANGENT EQUATION TO DETERMINE EQUILIBRIUM SHAPE OF HEADLAND BAY BEACHES
}

\author{
Jonathan Kemp ${ }^{1}$ Benoit Vandeputte ${ }^{2}$ Thomas Eccleshall ${ }^{3}$ Richard Simons ${ }^{4}$ Peter Troch ${ }^{5}$
}

\begin{abstract}
When designing any artificial beach, it's desirable to avoid (or minimise) future maintenance commitments by arranging the initial beach planshape so that it remains in equilibrium given the incident wave climate. Headlands bays, or embayments, where a sandy beach is held between two erosion resistant headlands, tend to evolve to a stable beach planshape with little movement of the beach contours over time. Several empirical bay shape equations have been derived to fit curves to the shoreline of headland bay beaches. One of the most widely adopted empirical equations is the parabolic bay shape equation, as it is the only equation that directly links the shoreline positions to the predominant wave direction and the point of diffraction. However, the main limitation with the application of the parabolic bay shape equation is locating the downcoast control point. As a result of research presented in this paper a new equation, based on the hyperbolic tangent shape equation was developed, which eliminates the requirement of placing the down coast control point and relies on defining a minimum beach width instead. This modified equation was incorporated into a new ArcGIS tool.
\end{abstract}

Keywords: Headland Bays; Coastal Engineering; stable beaches.

\section{INTRODUCTION}

Rocky coasts with headland bay beaches represent about $50 \%$ of the world's coastline (Short and Masselink, 1999). The term headland bay beach has been used to define a shoreline bounded by rocky outcrops or headlands, either natural or man-made, where the shoreline assumes some form of curvature. These headland bay beaches are common features of shorelines that experience incident waves from a predominant direction with the presence of at least one natural or artificial fixed point, leading to diffraction of incoming waves. It is widely known that the planshape of a beach is governed mainly by the wave induced currents; with headland-bay beaches the predominant waves are diffracted in such a way as to break simultaneously around the periphery of the bay once an equilibrium planshape has been established.

For coastal development projects, artificial beaches are an attractive feature and large scale coastal developments are being planned and constructed around the world at a remarkable rate. In the design of any artificial beach it is desirable to avoid, or minimise, any future maintenance commitments by designing the initial beach planshape in such a way that it remains relatively stable under the incident wave climate experienced. The preliminary design of artificial stable beaches has mainly been achieved through the application of the static equilibrium bay theory, which is based on empirical equations of natural headland bay beaches.

\section{SUMMARY OF HISTORY AND DEVELOPMENT OF STABLE BAY THEORY AND EQUATIONS}

The equilibrium beach planshape of headland bay beaches was identified as early as the 1900's and is generally a widely accepted concept today. The theory and details of the development of this has been described more comprehensively in many previous papers over the years (see for example Hsu et al. [2010]), but a summary of some of the chronological development of the theory and key equations is presented below for ease of reference to the reader:

- 1906 - Geologists and geographers first noted the beach planshape of headland bay beaches [Halligan, 1906].

- 1944 - Krumbein examined beach process of Half Moon Bay, California and suggested the approximation of a logarithmic spiral [Krumbein, 1944].

- 1960 - Silvester initiated research on the stability of crenulated shaped bays from a coastal engineers point of view with results reported from a physical model study showing an initially straight beach eroding to a stable curved bay [Silvester, 1960].

\footnotetext{
1 International Marine and Dredging Consultants, Antwerp, Belgium

2 Department of Civil Engineering, University of Ghent, Belgium

${ }^{3}$ Department of Civil, Environmental and Geomatic Engineering, University College London, UK

4 Department of Civil, Environmental and Geomatic Engineering, University College London, UK

5 Department of Civil Engineering, University of Ghent, Belgium
} 
- 1961 - Mashima first used the term parabolic to describe the geometric shape of stable coasts in Japan [Mashima, 1961].

- 1965 - Yasso applied a log spiral equation to four natural headland bay crenulated beaches in the US [Yasso, 1965].

- 1970's - Further work by Silvester and Ho advocated headland control for coastal engineering purposes, leading to the development of crenulated-shaped equilibrium beach planshape theory [Silvester, 1970; Silvester and Ho, 1972].

- $\quad 1987$ - Hsu et al showed that the log spiral does not follow the complete periphery of the bay from the model tests of Silvester and Ho [1972], therefore suggested a different equation is required [Hsu et al, 1987].

- 1989 - Hsu and Evans revisited the parabola equation and developed the parabolic equation for engineering purposes from fitting the planshape of 27 different beaches in static equilibrium. The origin of the equation, unlike the log spiral, is the wave diffraction point around the headland and the result is a beach planshape in static equilibrium. This makes the equation ideal for engineering purposes. It is also important to note that water levels were not believed to be important if the shoreline shape is considered at MHW [Hsu and Evans, 1989].

- 1993 - Silvester and Hsu proposed that in terms of beach stability, headland bay beaches can be classified as being in: (1) Dynamic Equilibrium; with continual sediment supply the shoreline may be further seaward of the static equilibrium position and the apparent stable shoreline position is maintained by the balance between sediment input and output. (2) Static Equilibrium; is a bay with almost negligible sediment input or output and is stable when the tangential section of downcoast is parallel to the wave crests. Waves will break simultaneously around the whole bay, meaning there is no longshore component of breaking wave energy and hence no littoral drift in the embayment. (3) Unstable; occurs when the beach is in an eroding state because of a reduction in sediment supply.

- 1997 - Silvester and Hsu advocated the use of headland control as a naturally functioning and preferable means of shore protection through the use of the parabolic equation [Silvester and Hsu, 1997].

- 1999 - Moreno and Kraus developed the hyperbolic tangent shape equation (HTSE) through the analysis of 46 beaches of mixed beach stability not exclusively beaches in static equilibrium. This equation can fit the shape of any bayed beach, regardless of whether it is in static or dynamic equilibrium or unstable [Moreno and Kraus, 1999].

- $\quad 2001$ - Gonzalez and Medina provide guidance on locating the downcoast control point [Gonzalez and Medina, 2001].

- 2002 - Parabolic equation is included in the Coastal Engineering Manual.

- 2004 - Overview of the applicability of the empirical equations delivered by Benedet et al. suggests that the preferred method is the parabolic equation [Benedet et al., 2004].

- 2008 - Hsu et al. introduces the additional beach classification: (4) Natural beach reshaping; as a result of the repositioning or extension of an updrift headland or coastal structure and compares the three main empirical bay shape equations [Hsu et al., 2008].

- 2010 - A review of the latest research and summary of static bay beach concept is provided by Hsu et al. [2010].

- 2010 - The sensitivity of locating the downcoast control point was studied by Lausman et al. and indicated that the placement of the control points is a subjective exercise [Lausman et al, 2010 and 2010a].

\section{EXISTING EMPIRICAL BAY SHAPE EQUATIONS AND THEIR LIMITATIONS}

Several empirical bay shape equations have been derived defining curves which fit the shoreline planshape of headland bay beaches. Wave heights and periods are not included in these expressions, although they were once investigated by Hsu and Evans, (1989) and found to be insignificant for bayed beaches in static equilibrium. There are three main empirical equations that have been used to assess the stability and design of headland bay beaches. These include the logarithmic spiral, the hyperbolic tangent equation and the parabolic equation.

All three equations are based on different controlling parameters, coordinate systems and origins. However, the logarithm-spiral and hyperbolic-tangent equations have been criticised more so than the 
parabolic. Klein et al. (2003) suggest that this is due to the fact that both the log-spiral and hyperbolic tangent do not use the upcoast headland in their definition sketch, co-ordinate system and mathematical formulation. The tip of the headland is however, an integral parameter in headland control and the concept of static equilibrium. It is the point of wave diffraction, which defines the approaching wave angle, controlling the stability of the bay. This is the main reason that much research in this field has concentrated upon using the parabolic equation to assess beach stability.

The parabolic equation is the only model which uses the headland as the centre of the coordinate system. It can therefore also be used as a mechanism for evaluating beach stability and predicting shoreline changes arising from structures built on a headland (Klein et al., 2003).

\section{Logarithmic Spiral Equation}

Krumbein (1944) and later Yasso (1965) applied a logarithmic spiral equation, to fit the curved periphery of bays in the U.S. A definition sketch, taken from Benedet et al. (2004), is given in Figure 1. The equation put forward was given in polar coordinates with the radius $r$ being a function of the angle $\theta$ (Lavalle and Lakhan, 1997):

$$
R_{2}=R_{l} \exp (\theta \cot \alpha)
$$

Where:

$\mathrm{R}=$ Radius from origin (radians)

$\theta=$ Angle between the dominant wave crest and the radius (degrees)

$\alpha=$ Constant angle of the tangent to the curve with radii R1 and R2 (degrees)

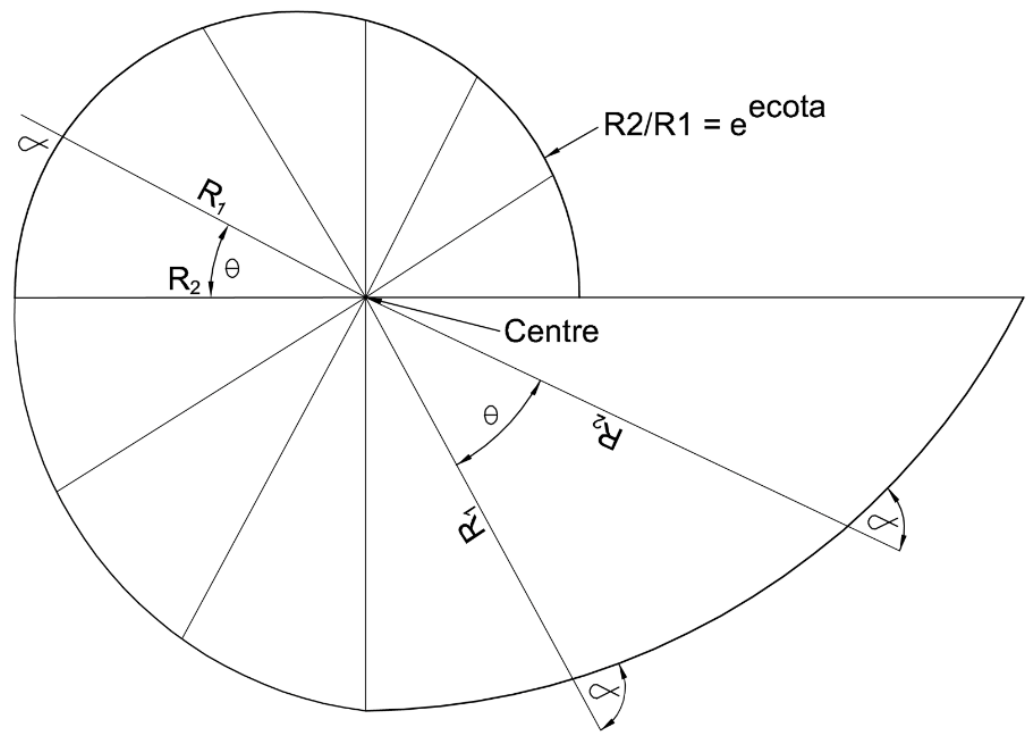

Figure 1 Definition sketch for the log spiral (from Hsu et al 2008)

Both Benedet et al. (2004) and Hsu et al. (2010) criticise the log-spiral equation for use in beach stability assessments for three main reasons:

- Due to its constant curvature, the equation does not fit the relatively straight section of the headland bay beach.

- Effective wave direction and the tip of the headland (point of wave diffraction) are not used and therefore it is not possible to predict the effect of relocating the headland (e.g. introduction of a coastal structure).

- The geometric centre of the log-spiral curve is offset from the headland tip and is found by trial and error.

In light of these disadvantages, two other empirical equations were developed: the hyperbolictangent and the parabolic equation. 


\section{Hyperbolic Tangent Shape Equation (HTSE)}

The hyperbolic tangent shape equation was introduced by Moreno and Kraus (1999) to simplify the fitting procedure and reduce ambiguity in arriving at an equilibrium shoreline shape as controlled by a single headland. Through the analysis of 46 beaches around Spain and North America the hyperbolic tangent shape equation was derived. The hyperbolic tangent shape equation is defined in a relative Cartesian co ordinate system (Figure 2) as:

$$
\mathrm{y}= \pm \mathrm{a} \operatorname{tanhm}(\mathrm{bx})
$$

Where:

$\mathrm{y}=$ Distance across shore $[\mathrm{m}]$

$\mathrm{a}=$ Empirically determined dimensional coefficient $[\mathrm{m}]$

$\mathrm{b}=$ Empirically determined dimensional coefficient $[\mathrm{m}]$

$\mathrm{m}=$ Empirically determined coefficient [dimensionless]

$\mathrm{x}=$ Distance alongshore $[\mathrm{m}]$

The hyperbolic Tangent Shape Equation produces a curve which is symmetric with the $\mathrm{x}$-axis and produces two asymptotes. These are found at $\mathrm{y}= \pm \mathrm{a}$. The line $\mathrm{y}=+\mathrm{a}$ indicates the location on the shoreline which is no longer under the influence of the headland.

The parameter a controls the magnitude of the asymptote (distance between the relative origin of coordinates and the location of the straight shoreline), $\mathrm{b}$ is a scaling factor controlling the approach to the asymptotic limit and $\mathrm{m}$ controls the curvature of the shape. These unknowns were found by using trial and error and an optimisation procedure that minimises rms errors. Based on the analysis of the 46 beaches, Moreno and Kraus (1999) proposed the following results:

$$
\begin{aligned}
& a b \cong 1.2 \\
& m \cong 0.5
\end{aligned}
$$

From which the values of the coefficient used in the hyperbolic tangent shape equation can be calculated.

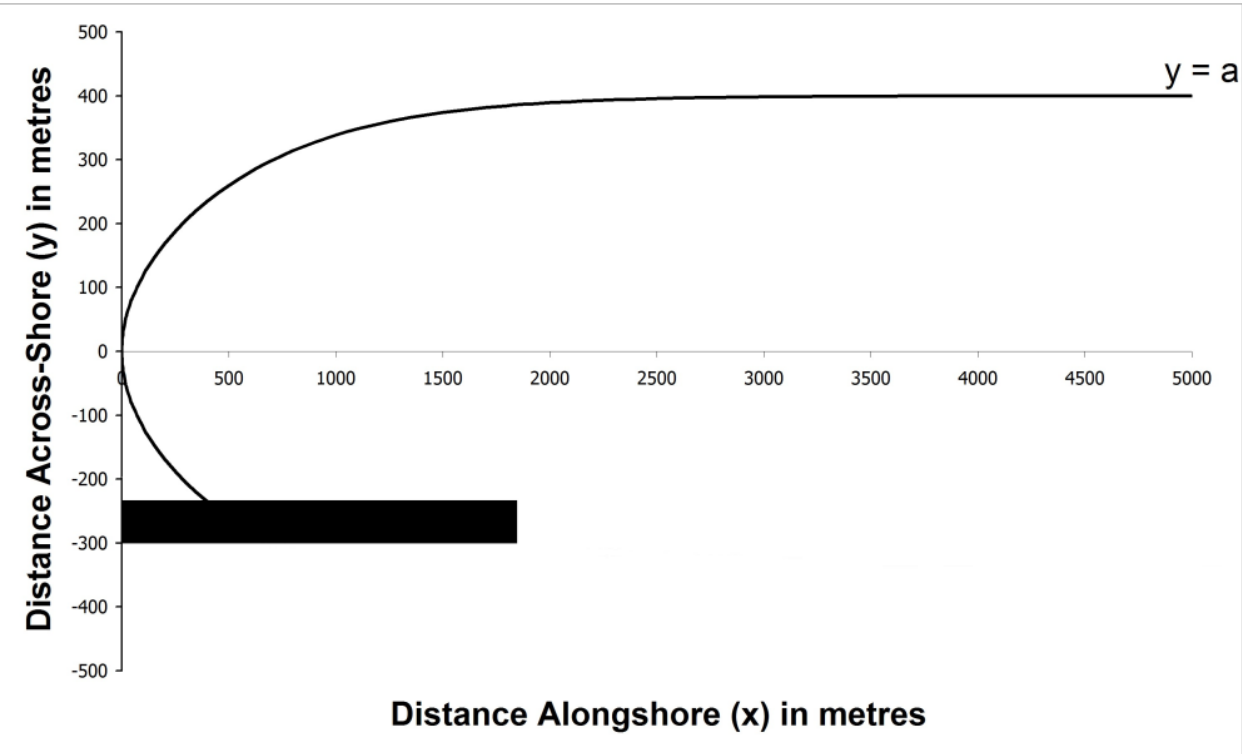

Figure 2 Definition sketch for hyperbolic tangent shape equation $(a=400 \mathrm{~m}, \mathrm{~b}=0.0009 \mathrm{~m}-1$ and $\mathrm{m}=0.5)$ (adapted from Martino et al., 2003)

The hyperbolic tangent shape equation, like the log-spiral, has undergone scrutiny for a number of reasons: 
- It fails to take into account the point of wave diffraction. This limits its potential for the design and application of management.

- The origin of the curve is insensitively found by trial and error, until the errors are minimal.

- Hsu et al. (2010) also noted that the equation can be applied to fit the planshape of any bay beach in static equilibrium or non-equilibrium and therefore cannot be used to assess the stability of a bay.

\section{Parabolic Bay Shape Equation (PBSE)}

The parabolic bay shape equation is a second order polynomial equation developed by Hsu and Evans (1989) from fitting the planshape of 27 mixed cases of prototype and model bays believed to be in static equilibrium (i.e. with no littoral drift):

$$
\frac{R}{R_{\beta}}=C_{0}+C_{1}\left(\frac{\beta}{\theta}\right)+C_{2}\left(\frac{\beta}{\theta}\right)^{2}
$$

where:

$\mathrm{R} \beta=$ Control line length

$\mathrm{R}=$ Radius to a point along the curve at an angle $\theta$

$\beta=$ Wave obliquity

$\mathrm{C}=$ Constants generated by regression analysis to fit the peripheries of the 27 prototype and model bays

$\theta=$ Angle between wave crest and radius to any point on the bay periphery in static equilibrium

The two basic parameters are the reference wave obliquity $\beta$ and control line length $R_{\beta}$ (Figure 4 ). The variable $\beta$ is a reference angle of wave obliquity or the angle between the incident wave crest (assumed linear) and the control line, joining the upcoast diffraction point to a point on the near straight beach downcoast point. The radius $R$ to any point on the bay periphery in static equilibrium is angled $\theta$ from the same wave crest line radiating from the point of wave diffraction upcoast. The three $\mathrm{C}$ constants, generated by regression analysis to fit the peripheries of the 27 prototype and model bays, differ with reference angle $\beta$. Numerically, these coefficients may be expressed by fourth order polynomials (to three significant numbers) as follows:

$$
\begin{aligned}
& C_{0}=0.0000000479 \beta^{4}-0.00000879 \beta^{3}+0.000352 \beta^{2}-0.00479 \beta+0.0715 \\
& \mathrm{C}_{1}=-0.000000128 \beta^{4}+0.0000182 \beta^{3}-0.000487 \beta^{2}+0.00771 \beta+0.955 \\
& \mathrm{C}_{2}=0.0000000944 \beta^{4}-0.0000120 \beta^{3}+0.000316 \beta^{2}-0.00828 \beta+0.0265
\end{aligned}
$$

These values of $\mathrm{C}$ are bounded within 2.5 and -1.0 for the usual range of angle $\beta$ from $10^{\circ}$ to $80^{\circ}$ applicable in most field conditions. For $\theta=\beta$, the condition $R=R_{\beta}$ must be met which forces $C_{0}+C_{l}$ $+C_{2}=1$ by equation 5 (Moreno and Kraus, 1999). For a headland bay beach with a given set of $\beta$ and $R_{\beta}$, locations for pairs of $R$ and $\theta$ can be marked on the existing shoreline, and a curve can be drawn for the static equilibrium bay shape prediction. 


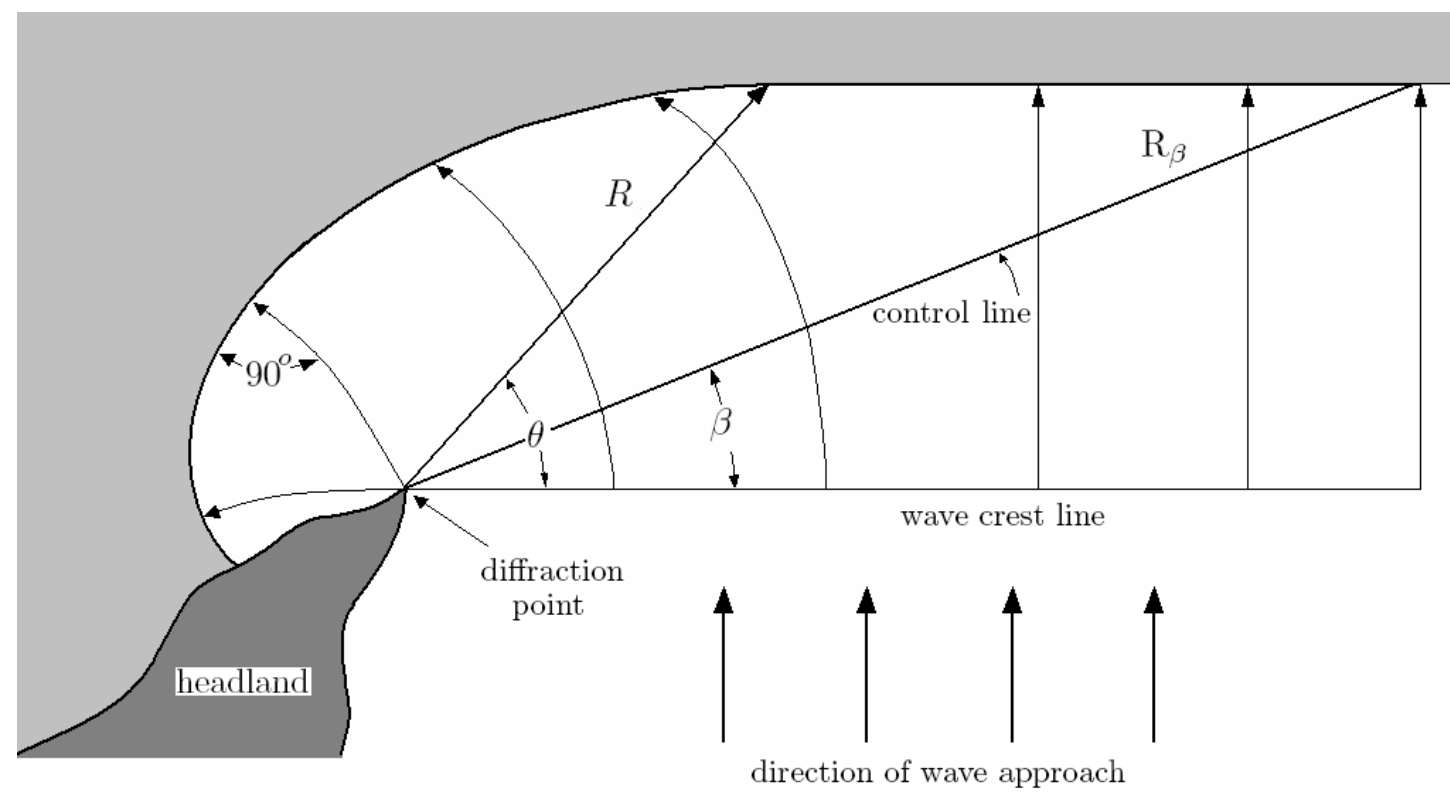

Figure 3 Definition sketch for the parabolic equations (modified from Hsu and Evans, 1989)

In contrast to the log-spiral and the hyperbolic tangent shape equation, the parabolic bay shape equation links the change of the shoreline to the point of wave diffraction upcoast. The physical location of the wave diffraction point (i.e. the tip of the headland or coastal structure) is used as the origin of the co-ordinate system for the parabolic equation. Therefore the effect of relocating the point of diffraction, by introducing structures for example, can then be assessed. The parabolic bay shape equation is currently the most widely adopted for the assessment of headland bay beach stability and the effects of coastal structures on headland bay beaches.

However, the selection of the end point or downcoast point and wave obliquity must be made from careful interpretation and understanding of coastal morphology; automatic curve fitting is not an option. There are several interpretations of the downcoast control point of the parabolic bay shape equation (as shown in Table 1), but it is generally understood that the downcoast control point is located where the beach starts to become straight and therefore free from the direct influence of the headland. The sensitivity of locating the downcoast control point was studied by Lausman et al. (2010). Lausman et al. (2010) tested volunteers by asking them to choose the various control points, firstly without showing the outputs to them, and secondly by showing the results to the participants. The researchers found that there was a much smaller variation in the position of the static equilibrium beach planshape, resulting in more accurate findings when users were permitted to see the results immediately after elicitation.

It can therefore be considered that the main limitation with the application of the parabolic equation is locating the downcoast control point.

\begin{tabular}{|c|l|}
\hline \multicolumn{2}{|c|}{ Table 1 Interpretation of the downcoast control points [adapted from Lausman, 2010] } \\
\hline Author & Interpretation of the downcoast control points \\
\hline $\begin{array}{c}\text { Hsu et al } \\
(1993)\end{array}$ & The down coast limit of the bay: generally the limit of the straightening beach. \\
\hline $\begin{array}{c}\text { Short and } \\
\text { Masselink } \\
(1999)\end{array}$ & $\begin{array}{c}\text { The second control point (downcoast control point) may be a second headland or, } \\
\text { if the latter is not present, can be taken as the start of the straight section of the } \\
\text { coastline where the shoreline orientation is parallel to the incident wave crests }\end{array}$ \\
\hline $\begin{array}{c}\text { Gonazalez } \\
\text { and Medina } \\
(2001)\end{array}$ & $\begin{array}{l}\text { Provided guidance on the location of the control point, proposing a parameter } \\
\text { called } \alpha \text { min as a function of the relative location of the structure and the original } \\
\text { shoreline and the wavelength. Problems arise with short or incomplete plan } \\
\text { shapes, meaning that the straight stretch of coast is lacking, and therefore, the } \\
\text { control point becomes a 'virtual' point. Distance to the original shoreline is } \\
\text { difficult to assess in some situations. }\end{array}$ \\
\hline
\end{tabular}




\begin{tabular}{|c|l|}
\hline $\begin{array}{c}\text { Klein et al. } \\
(2003)\end{array}$ & $\begin{array}{l}\text { It is worth noting that any point on or near the straight down coast segment of the } \\
\text { beach could be conveniently chosen as a downcoast control point, for which the } \\
\text { convenience and insensitivity was noted in SILVESTER AND HSU }(1993,1997)\end{array}$ \\
\hline $\begin{array}{c}\text { Benedet et } \\
\text { al (2004) }\end{array}$ & $\begin{array}{l}\text { The end point is located when the beach starts to become straight therefore free } \\
\text { from the direct influence of the headland. }\end{array}$ \\
\hline $\begin{array}{c}\text { Martino et } \\
\text { al. (2005) }\end{array}$ & $\begin{array}{l}\text { For the parabolic shape, the control point is a boundary for the curved section of } \\
\text { the beach controlled by diffraction and the straight section of beach perpendicular } \\
\text { to the assumed predominant wave direction. }\end{array}$ \\
\hline
\end{tabular}

\section{THE RESEARCH PROBLEM}

Much of the research to date focuses on the assessment of the stability of existing beaches and how to manage existing beaches; there is comparatively little published material on the design of new artificial beaches for coastal development projects. When there is no existing beach, as in the situation of designing new beaches, the process of selecting a suitable downcoast control point becomes even more problematic, as illustrated in Figure 4. Gonzalez and Medina [2001] stated that the Hsu and Evans [1989] methodology therefore cannot be used for design purposes because there is no shoreline to determine the location.

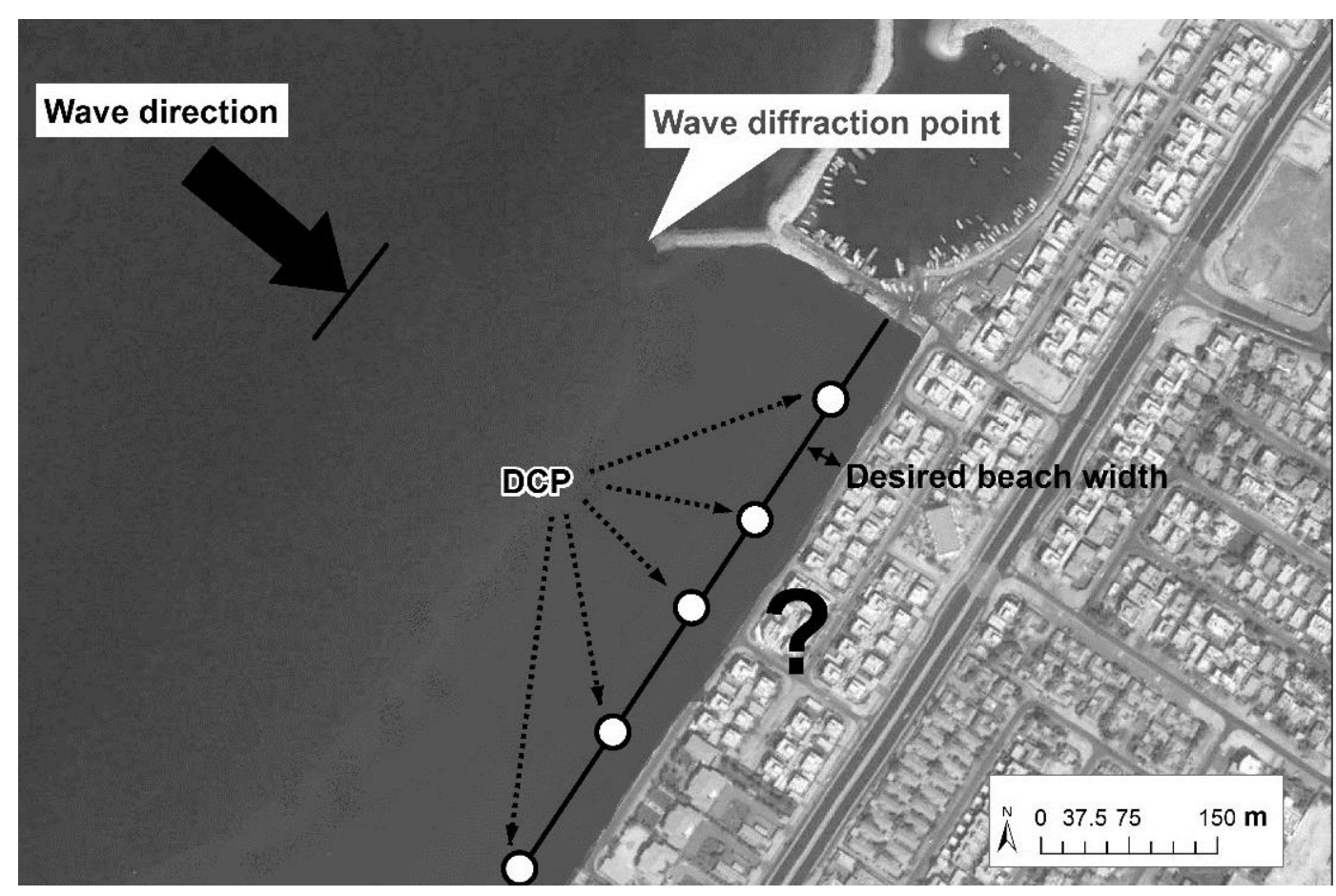

Figure 4 Problems with identifying the location of the downcoast control point in the parabolic equation

Several researchers have used other methods such as modelling to determine the location of the downcoast control point. For example, Eccleshall [2009] and Lausman et al. [2010a] both investigated the use of the wave model RefDif to help determine the downcoast control point, while Yu and Hsu [2006] used the beach model GENESIS. However, the implementation of detailed numerical modelling somewhat defeats the purpose of applying an empirical equation. Therefore, the main aim of the research presented in this paper was to use a different approach and to revisit the hyperbolic tangent bay shape equation. The work reported here has therefore set out to determine a relationship linking the existing hyperbolic tangent shape equation with the wave diffraction point and wave obliquity. This would then eliminate the ambiguity of locating the downcoast control point associated with the parabolic bay shape equation.

The rest of this paper presents the methodology and application of the modified hyperbolic tangent bay shape equation. 


\section{METHODOLOGY}

\section{Case studies}

In order to overcome the major shortcoming of the hyperbolic tangent equation, a relationship linking the geometric origin of the hyperbolic tangent equation with a wave diffraction point needed to be determined. To do this, a database of case studies was developed comprising of 46 beaches in Spain, Southern France and North-Africa (Figure 5). Data were sought for beaches extending from relatively small project scale (hundreds of metres) to larger scale (up to a few kilometres). The case studies were selected based on several requirements: they show a crenulated bay shape; have only one headland, so that a straight section of the beach can be seen; and were in equilibrium.

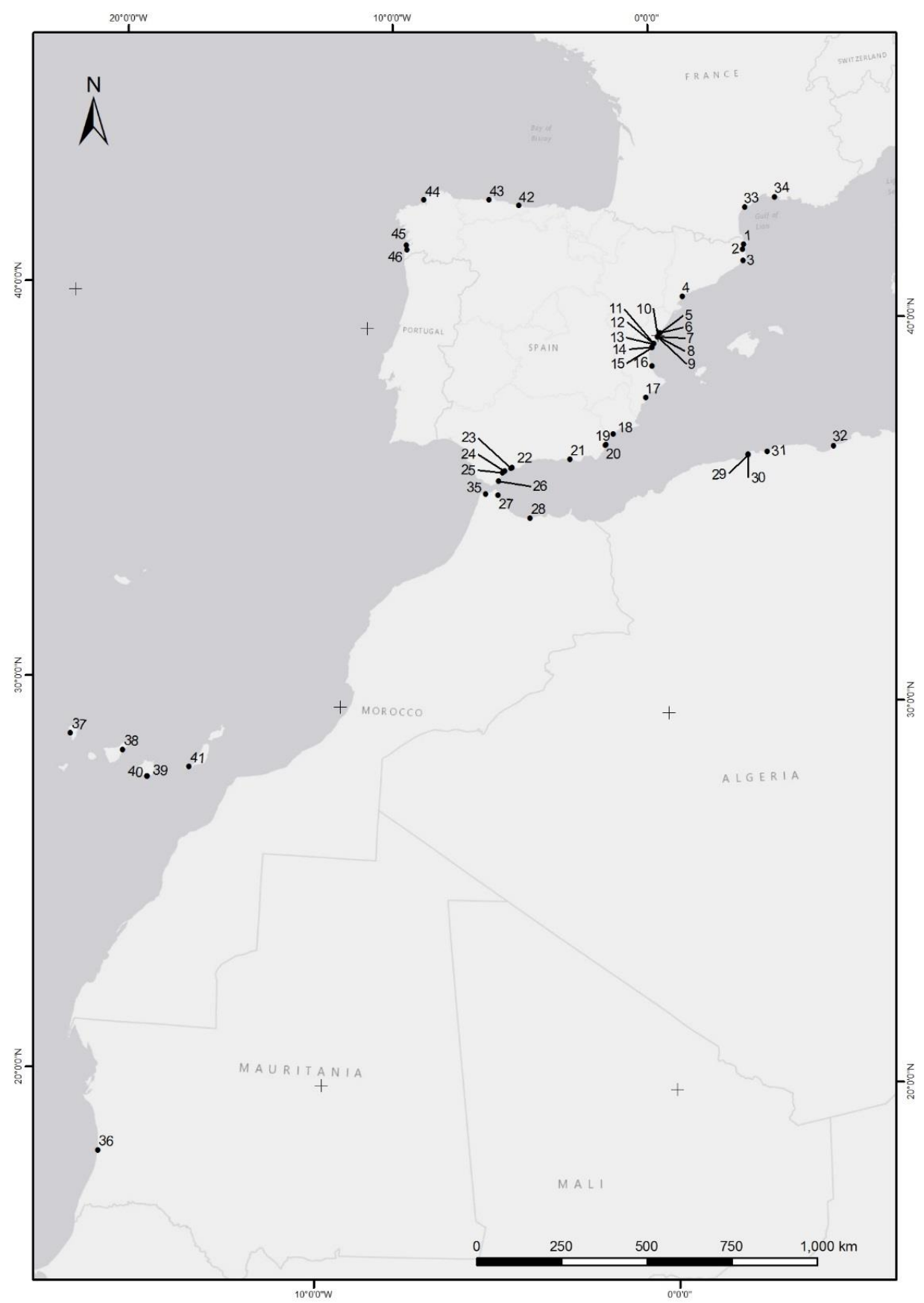

Figure 5 Location of case studies 


\section{Determining $a, b$ and $\boldsymbol{m}$ coefficients for HTSE}

The shorelines of all the case study beaches were carefully digitised in ArcGIS from high quality aerial images. These digitised shorelines were then imported into Matab to determine the coefficients $a, b$ and $m$ of the hyperbolic tangent shape equation. This was achieved by means of the built-in curve fitting application in the software package of Matlab.

The best-fit hyperbolic curve was established based on a minimal value for the sum of squares due to error (SSE). This statistic measures the total deviation of the response values from the fit to the response values. It is also called the sum of squared residuals and is given by

$$
S S E=\sum_{i=1}^{n}\left(y_{i}-a \tanh ^{m}\left(b x_{i}\right)\right)^{2}
$$

where $\left(x \_i, y \_i\right)=$ the coordinates of the transformed points, in its defined relative Cartesian coordinate system. From this a best-fit curve was obtained. The three coefficients together with their 95\% confidence limits and the values for the goodness-of-fit statistics were obtained and the objective of determining the coefficients for the HTSE for beaches in equilbirum was achieved. Figure 6 shows the best-fit hyperbolic tangent function of the Port de Sagunt beach in Puerto de Sagunto, together with the obtained coefficients and the corresponding goodness-of-fit-statistics.
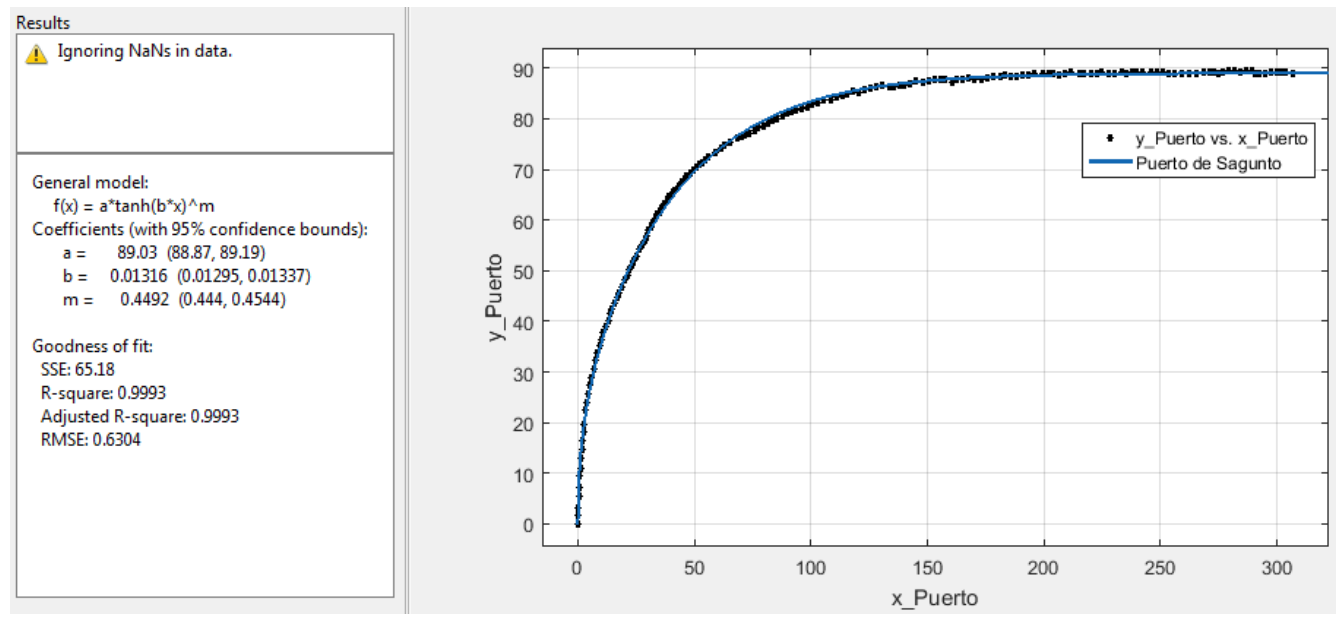

Figure 6 Plot of the best-fit hyperbolic tangent function of the Port de Sagunt beach, together with the obtained coefficients and the corresponding goodness-of-fit-statistics.

The values of the $m$ coefficient for the 46 beaches investigated, support the original findings of Moreno and Kraus [1999] that $\mathrm{m} \approx 0.5$. Although with a standard deviation of 0.05 compared to 0.13 in the study of Moreno and Kraus (1999), a narrower confidence interval was observed in this investigation.

To estimate the correlation between $a$ and $b$, least-squares fitting for a power function between them was carried out. Figure 7 gives a plot of all the points together with the plot of best-fit line. 


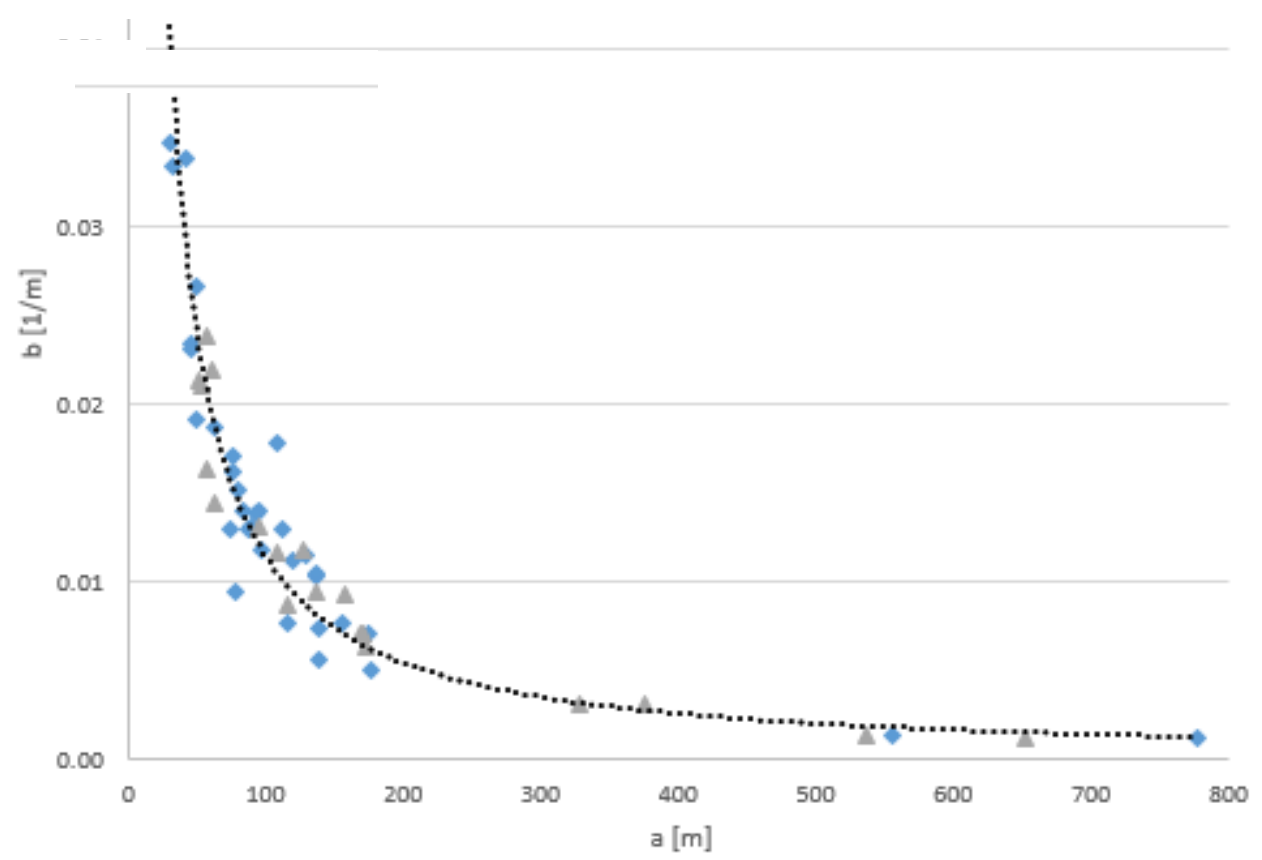

Figure 7. Values for coefficient $b$ in function of coefficient $a$, together with the best-fit line.

The following relationship between the coefficients $a$ and $b$ was determined:

$$
b=1.794 \cdot a^{-1.097}
$$

$$
R^{2}=0.9372
$$

This relationship for the a and $b$ coefficients is different to the one determined for the original HTSE by Moreno and Kraus (1999). However, this relationship is based on beaches only in equilibrium and the $\mathrm{R}^{2}$ value is better (0.9372) compared to the one for the data used by Moreno and Kraus (0.8696). In light of this, it is proposed to use the new relationship for the $a$ and $b$ coefficients.

The hyperbolic tangent shape equation (HTSE), was then modified in accordance with the results above to allow it to determine beaches in equilibrium. Substituting the coefficients $m$ and $b$ by using the obtained relationships, results in the following Equation with only coefficient $a$ as parameter:

$$
y= \pm a \tanh ^{0.496}\left(1.794 \cdot a^{-1.097} x\right)
$$

The next step was to translate the HTSE in such a way that the wave diffraction point coincides with the origin of the new relative coordinate system.

\section{Determining the wave diffraction point for HTSE}

Further analysis was carried out to determine the location of the diffraction point relative to the origin of the hyperbolic tangent equation. This analysis involved investigating the coordinates of the diffraction point on an axis where the "origin" of the hyperbolic tangent shape equation is at $(0,0)$. The definitions of the different coefficients are shown in Figure 8. 


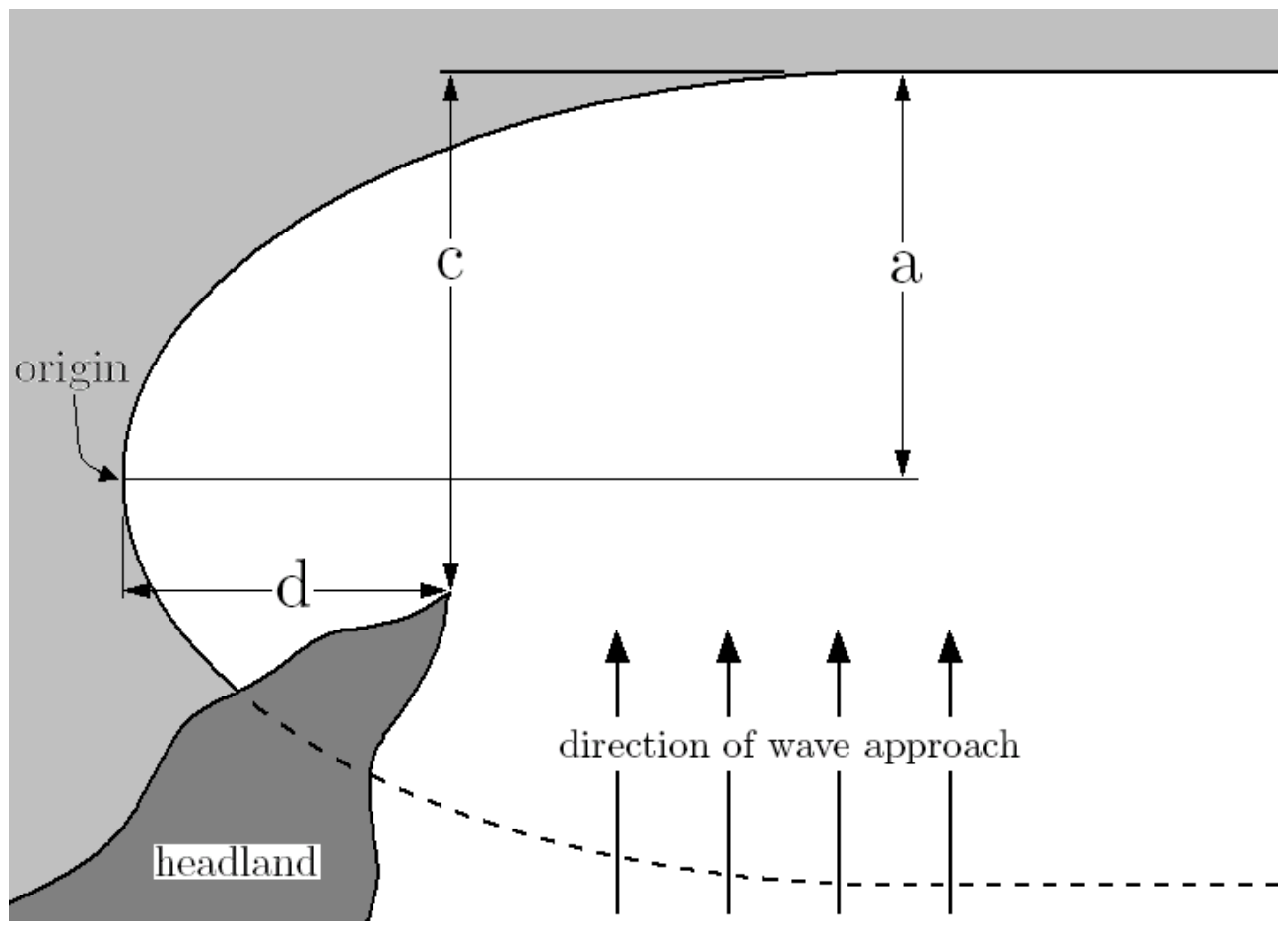

Figure 8 Definition sketch of parameters for the modified hyperbolic tangent equation

For any modification of the hyperbolic tangent equation to be applicable for designing new beaches or assessing the influence of a headland on a beach, the coordinates of the diffraction point need to be determined as non-dimensional expressions. For the purpose of analysis, the coordinates of the diffraction point are defined as ' $c$ ' and ' $d$ ' (shown in Figure 8). This means they can be used for any scale of headland bay. To achieve this, a scaling distance was measured for each bay. The coordinates of the diffraction point were then divided by this scaling distance, thus producing a non-dimensional expression that can be applied to different sized bays. The measurement which was determined to be the most easily obtainable was the value ' $a$ '. This was the distance between the $x=0$ line and the straight section of the beach. In designing new beaches the width of beach, from the back of the beach to the waterline, is often given as a design criterion or client requirement (e.g. a certain beach width required for coast protection or required for a number of sun loungers on the beach). The values of dimensionless coefficients resulting from the analysis are shown in Table 1.

The analysis of the 46 case studies showed that a clear pattern emerged: the diffraction point always occurred in a similar location. This led to the following relationships, which were used to identify the location of the coordinates of the wave diffraction point for the hyperbolic tangent equation:

$c / a \cong 1.256$ for the $x$ coordinate

$d / a \cong 0.517$ for the $y$ coordinate 


\begin{tabular}{|c|c|c|c|c|c|c|c|c|}
\hline \# & a & b & $\mathrm{m}$ & C & d & $c / a$ & $d / a$ & $a . b$ \\
\hline 1 & 776.6 & 0.001 & 0.57 & 960.9 & 356.3 & 1.24 & 0.46 & 0.97 \\
\hline 2 & 50.2 & 0.027 & 0.57 & 61.0 & 15.7 & 1.21 & 0.31 & 1.34 \\
\hline 3 & 86.6 & 0.013 & 0.52 & 110.1 & 40.8 & 1.27 & 0.47 & 1.12 \\
\hline 4 & 555.3 & 0.001 & 0.46 & 643.4 & 195.0 & 1.16 & 0.35 & 0.78 \\
\hline 5 & 137.0 & 0.010 & 0.59 & 176.9 & 70.9 & 1.29 & 0.52 & 1.40 \\
\hline 6 & 136.3 & 0.010 & 0.51 & 173.2 & 73.2 & 1.27 & 0.54 & 1.42 \\
\hline 7 & 62.0 & 0.019 & 0.53 & 77.1 & 35.8 & 1.24 & 0.58 & 1.15 \\
\hline 8 & 94.1 & 0.014 & 0.47 & 110.1 & 37.8 & 1.17 & 0.40 & 1.32 \\
\hline 9 & 74.1 & 0.013 & 0.50 & 95.5 & 38.4 & 1.29 & 0.52 & 0.96 \\
\hline 10 & 119.8 & 0.011 & 0.52 & 147.3 & 53.9 & 1.23 & 0.45 & 1.35 \\
\hline 11 & 31.6 & 0.033 & 0.49 & 41.5 & 16.9 & 1.31 & 0.53 & 1.05 \\
\hline 12 & 45.8 & 0.023 & 0.58 & 64.0 & 29.8 & 1.40 & 0.65 & 1.07 \\
\hline 13 & 156.1 & 0.008 & 0.43 & 184.0 & 71.9 & 1.18 & 0.46 & 1.19 \\
\hline 14 & 46.1 & 0.023 & 0.45 & 56.7 & 24.3 & 1.23 & 0.53 & 1.06 \\
\hline 15 & 89.0 & 0.013 & 0.45 & 108.6 & 37.8 & 1.22 & 0.42 & 1.17 \\
\hline 16 & 827.8 & 0.001 & 0.67 & 1184.4 & 234.2 & 1.43 & 0.28 & 0.78 \\
\hline 17 & 139.1 & 0.007 & 0.48 & 153.2 & 56.8 & 1.10 & 0.41 & 1.02 \\
\hline 18 & 128.6 & 0.011 & 0.57 & 163.4 & 75.5 & 1.27 & 0.59 & 1.48 \\
\hline 19 & 107.5 & 0.018 & 0.46 & 132.6 & 46.3 & 1.23 & 0.43 & 1.90 \\
\hline 20 & 49.5 & 0.019 & 0.54 & 65.3 & 25.7 & 1.32 & 0.52 & 0.95 \\
\hline 21 & 111.8 & 0.013 & 0.45 & 138.0 & 61.7 & 1.23 & 0.55 & 1.44 \\
\hline 22 & 79.5 & 0.015 & 0.54 & 99.3 & 46.0 & 1.25 & 0.58 & 1.21 \\
\hline 23 & 93.6 & 0.014 & 0.48 & 116.8 & 48.7 & 1.25 & 0.52 & 1.30 \\
\hline 24 & 175.5 & 0.005 & 0.47 & 210.1 & 69.8 & 1.20 & 0.40 & 0.88 \\
\hline 25 & 96.8 & 0.012 & 0.50 & 121.2 & 54.5 & 1.25 & 0.56 & 1.14 \\
\hline 26 & 30.5 & 0.035 & 0.55 & 39.6 & 16.2 & 1.30 & 0.53 & 1.06 \\
\hline 27 & 139.0 & 0.006 & 0.44 & 166.0 & 65.8 & 1.19 & 0.47 & 0.77 \\
\hline 28 & 174.8 & 0.007 & 0.45 & 215.3 & 90.0 & 1.23 & 0.52 & 1.23 \\
\hline 29 & 83.6 & 0.014 & 0.58 & 107.5 & 47.6 & 1.29 & 0.57 & 1.17 \\
\hline 30 & 76.1 & 0.016 & 0.50 & 100.6 & 37.2 & 1.32 & 0.49 & 1.23 \\
\hline 31 & 78.0 & 0.009 & 0.49 & 98.4 & 26.4 & 1.26 & 0.34 & 0.74 \\
\hline 32 & 115.0 & 0.008 & 0.49 & 143.3 & 52.2 & 1.25 & 0.45 & 0.89 \\
\hline 33 & 75.1 & 0.017 & 0.49 & 97.9 & 36.4 & 1.30 & 0.49 & 1.28 \\
\hline 34 & 42.7 & 0.034 & 0.57 & 51.0 & 22.2 & 1.20 & 0.52 & 1.44 \\
\hline 35 & 25.4 & 0.043 & 0.52 & 38.3 & 7.3 & 1.51 & 0.29 & 1.10 \\
\hline 36 & 126.7 & 0.012 & 0.57 & 158.3 & 81.8 & 1.25 & 0.65 & 1.50 \\
\hline 37 & 136.0 & 0.009 & 0.44 & 197.4 & 100.2 & 1.45 & 0.74 & 1.29 \\
\hline 38 & 56.3 & 0.024 & 0.52 & 64.5 & 29.9 & 1.14 & 0.53 & 1.34 \\
\hline 39 & 57.3 & 0.016 & 0.52 & 77.8 & 22.2 & 1.36 & 0.39 & 0.93 \\
\hline 40 & 62.5 & 0.014 & 0.47 & 79.4 & 23.7 & 1.27 & 0.38 & 0.90 \\
\hline 41 & 106.0 & 0.009 & 0.64 & 151.5 & 73.3 & 1.43 & 0.69 & 0.97 \\
\hline 42 & 146.9 & 0.015 & 0.56 & 167.9 & 45.6 & 1.14 & 0.31 & 2.25 \\
\hline 43 & 537.0 & 0.001 & 0.48 & 693.9 & 145.8 & 1.29 & 0.27 & 0.73 \\
\hline 44 & 99.6 & 0.014 & 0.65 & 158.3 & 55.0 & 1.59 & 0.55 & 1.39 \\
\hline 45 & 53.3 & 0.021 & 0.56 & 92.4 & 34.8 & 1.73 & 0.65 & 1.12 \\
\hline 46 & 327.4 & 0.003 & 0.52 & 407.6 & 203.3 & 1.24 & 0.62 & 1.01 \\
\hline
\end{tabular}




\section{Development of a modified hyperbolic tangent shape equation}

Having determined the coordinates of the wave diffraction point, a modified hyperbolic tangent shape equation was developed:

$$
y=\left( \pm 0.796 c \tanh ^{0.496}\left(\frac{2.304}{c^{1.097}} \cdot(x+0.412 c)\right)+0.204 c\right.
$$

where:

$y=$ Distance cross shore $[\mathrm{m}]$

$x=$ Distance along shore $[\mathrm{m}]$

$c=$ Orthogonal distance between straight section of the beach and the point of wave diffraction [m]

As with the original hyperbolic tangent shape equation, the modified hyperbolic tangent shape equation is rotated so that the straight section of the equation produced is parallel to the wave crests of the approach wave.

The modified hyperbolic tangent shape equation also produces a curve which is symmetric with the $\mathrm{x}$-axis and produces two asymptotes. These are found at $\mathrm{y}= \pm 0.796 \mathrm{c}$. The line $\mathrm{y}=+0.796 \mathrm{c}$ indicates the location on the shoreline that is no longer under the influence of the headland. As the hyperbolic tangent shape equation produces a curve which is symmetric with the $\mathrm{x}$-axis and produces two asymptotes it removes the difficulty in locating the position of the downcoast control point. Only the 'c' position is required, which is directly related to the beach width.

Therefore, the application of the modified hyperbolic tangent equation requires only the following inputs:

1. Wave diffraction point

2. Wave direction

3. Defined beach width (usually a design parameter for either coast protection or amenity value).

\section{Application of modified hyperbolic tangent equation}

In order to streamline the application of both the parabolic bay shape equation and the modified hyperbolic tangent shape equation a new tool was developed in ArcGIS, although of course any other form of code can be used to apply the equations.

To use the tool the user simply defines the wave diffraction point by clicking on the headland, defines the wave direction in the tool and then defines the beach width. The tool then plots the result of the modified hyperbolic tangent equation graphically within GIS as a shapefile, overlaying an image or map of the existing beach or proposed development, along with any other data layers.

The calculation and plotting of the resulting shoreline position is instantaneous, which makes it a very useful tool in the armoury of the coastal engineer. It offers an intuitive environment with simple inputs and instant visualisation of the results and because the output files are in a standard GIS format they can be distributed to other users (e.g. coastal managers, clients or developers) to input into their own GIS for further examination. The tool provides information in a text format for all the output parameters associated with the parabolic bay shape equation. As the tool is embedded within GIS it can also be used in the estimation of the volume of sand required for beach nourishment and through using the other GIS functions a 3d view of the beach can be generated. By combining the modified hyperbolic tangent shape equation with GIS allows a simple first-step method in the preliminary design of proposed artificial beaches, offering an intuitive environment with simple inputs and instant visualisation of the results.

\section{CONCLUSIONS}

The three major empirical equations discussed, differ in mathematical functions, coordinate systems, origins and controlling parameters related to wave direction and bay geometry.

The parabolic bay shape equation is currently widely adopted for the assessment of headland bay beach stability and the effects of coastal structures on headland bay beaches. The main limitation with the application of the parabolic bay shape equation is locating the downcoast control point and the main limitation with the existing hyperbolic tangent shape equation is the lack of a tangible wave diffraction point. To overcome this limitation the work reported here has determined a relationship linking the existing hyperbolic tangent shape equation with the wave diffraction point (i.e. the headland) and has resulted in a modified hyperbolic tangent shape equation. 
Applying the modified hyperbolic tangent shape equation only requires the following inputs: the dominant wave direction, the diffraction point and the beach width. In designing new beaches, the width of beach, from the back of the beach to the shoreline, is often given as a design criterion or client requirement. This has eliminated the ambiguity of locating the downcoast control point associated with the parabolic bay shape equation.

To aid in the application of the methodology a new tool has been developed in ArcGIS. The calculation and plotting of the resulting shoreline position is instantaneous, which makes it a very useful tool in the armoury of the coastal engineer

\section{REFERENCES}

Benedet L, Klein AHF, and Hsu JRC [2004]. Practical insights and applicability of empirical bay shape equations. Proceedings 29th International Conference of Coastal Engineering. 2181-2193.

Eccleshall T, [2009]. Design of crenulate bays. Master thesis report. University College London. $104 p p$.

González M and Medina R [2001]. On the application of static equilibrium bay formulations to natural and man-made beaches. Coastal Engineering, 43, 209-225.

Halligan GH [1906]. Sand movement on the New South Wales coast. Proceedings Limnology Society, New South Wales, 31: 619-640.

Hsu JRC, Silvester R and Xia YM [1987]. New characteristics of equilibrium shaped bays. Proceedings of 8th Australian conf. on coastal and Ocean Eng., 3986-3999.

Hsu JRC and Evans C [1989], Parabolic bay shapes and applications. Proceedings of Institution of Civil Engineers. Part 2, vol 87. Thomas Telford, London, 557-570.

Hsu JRC, Benedet L, Klein AHF, Raabe ALA, Tsai CP and Hsu TW [2008]. Appreciation of static bay beach concept for coastal management and protection. Journal of Coastal Research, 24, 198-215.

Hsu JRC, Yu MJ and Benedet L [2010]. Static bay beach concept for scientists and engineers: a review. Coastal Engineering, 57, 76-91.

Krumbein WC [1944]. Shore processes and beach characteristics. Technical Memorandum No.3. Beach Erosion Board, U.S. Army Corps of Engineers. 47pp.

Lausman R, Klein AHF and Stive M [2010]. Uncertainty in the application of the parabolic bay shape equation: part 1. Coastal Engineering, 57, 142-151.

Lausman R, Klein AHF and Stive M [2010a]. Uncertainty in the application of the parabolic bay shape equation: part 2. Coastal Engineering, 57, 142-151.

Lavalle PD and Lakhan VC (1997) A spatial-temporal analysis of the development of a log-spiral shaped embayment. Earth Surface Processes and Landforms, 22, 657-667.

Martino E, Moreno L, and Kraus NC [2003]. Engineering guidance for the use of bayed-beach formulations. Proceedings of Coastal Sediments 2003: American Society of Civil Engineers, vol 3, 860-875

Mashima Y [1960]. Stable configuration of coastline. Coastal Engineering in Japan, 4:47-59.

Moreno L and Kraus NC [1999]. Equilibrium shape of headland-bay beaches for engineering design. Proceedings of Coastal Sediments 1999:American Society of Civil Engineers, vol 1, 860-875.

Oliveira FSB and Barreiro OM [2010]. Application of empircal models to bay-shaped beaches in Portugual. Coastal Engineering 57, 124-131.

Short AD and Masselink G [1999]. Embayed and structurally controlled beaches, in: Short, A.D. (Editor], Handbook of Beach and Shoreface morphodynamics. New York: John Willey; \& Sons, 230-249.

Silvester R [1960]. Stabilization of sedimentary coastlines. Nature, 188:467-469.

Silvester R [1970]. Development of crenulate shaped bays to equilibrium. J. Waterways and Harbours division, 96, 275-287.

Silvester R and Ho SK [1972]. Use of crenulated shaped bays to stabilize coasts. Proceedings 13th ICCE, 2, 1347-1365.

Silvester R [1985]. Natural headland control of beaches. Continental Shelf Research, 4, 581-596.

Silvester R and Hsu JRC [1993]. Coastal stabilisation: Innovative concepts. Prentice-Hall, 578p.

Silvester R and Hsu JRC [1997]. Coastal Stabilization. Singapore: World Scientific Publishing, 578p.

Yasso WE [1965]. Plan geometry of headland bay beaches. Journal of geology, 73, 702-714.

$\mathrm{Yu}$ MMJ and Hsu JRC [2006]. Parabolic bay shape equation revisited for practical applications. Proceedings 30th International Conference of Coastal Engineering. Vol. 4. ASCE 3478- 
3490.Battjes, J.A., and J.P.F.M. Janssen. 1978. Energy loss and set-up due to breaking of random waves, Proceedings of $14^{\text {th }}$ International Conference on Coastal Engineering, ASCE, 466-480.

De Vriend, H.J., J. Zyserman, J. Nicholson, J.A. Roelvink, P. Pechon, and H.N. Southgate. 1993. Medium-term 2DH coastal area modeling, Coastal Engineering, 21, 193-224.

Wiegel, R.L. 1965. Oceanographical Engineering, Prentice-Hall, Englewood Cliffs, New Jersey, 531 pp. 